${ }^{5}$ Lawlor F, Peiris S. Progress of a harlequin fetus treated with etretinate. J R Soc Med 1985;78:(suppl 11):19-20.

6 Buxman MM, Goodkin PE, Fahrenbach WH, Dimond RL. Harlequin ichthyosis with epidermal lipid abnormality. Arch Dermatol 1979;115:189-93.
Correspondence to Dr PS Ward, Paediatric Department, Addenbrooke's Hospital, Hills Road, Cambridge CB2 $2 Q Q$.

Accepted 20 March 1989

\title{
Effect of dystonic movements on oesophageal peristalsis in Sandifer's syndrome
}

\author{
J W L PUNTIS, H L SMITH, R G BUICK, AND I W BOOTH \\ Institute of Child Health, University of Birmingham
}

SUMmary A 5 year old girl with gross gastrooesophageal reflux had pronounced dystonic neck movements that resolved after fundoplication and resolution of the oesophagitis (Sandifer's syndrome). Oesophageal manometry before operation showed that peristalsis improved when she tilted her head to one side. Dystonic posturing may promote acid clearance from the distal oesophagus.

\section{Case report}

A 5 year old girl was referred with a 12 week history of belching and vomiting, mainly after food. A barium swallow examination was reported to show the presence of a hiatus hernia. Her appetite had decreased appreciably, and she was thought to have lost weight. She vomited about three times a day; occasionally altered blood was present in the vomit. Her general health had been good, although she had an operation for squint, had had grommets inserted, and had a history of urinary tract infections. On physical examination she looked well though pale, and was on the 50th centile for both height and weight. The most striking feature was pronounced neck dystonia with repeated rotation of the neck and tilting of the head towards the left shoulder (fig 1), sometimes associated with bending the upper part of her body to the left. No other abnormalities were found on neurological examination, and the dystonic movements stopped when she was asleep.

\section{INVESTIGATIONS}

Her haemoglobin concentration was $91 \mathrm{~g} / \mathrm{l}$ with a microcytic film, and the platelet count was raised at $680 \times 10^{9} / 1$, suggesting chronic blood loss. Microscopy of her sputum showed fat laden macrophages consistent with recurrent aspiration, and 24 hour oesophageal $\mathrm{pH}$ monitoring confirmed severe gastro-oesophageal reflux, with a reflux index (percentage of time the $\mathrm{pH}$ was less than 4 in the lower oesophagus) of $39 \%$ (normal $<4 \%$ ). A severe ulcerative oesophagitis of the lower half of the oesophagus was found at endoscopy and confirmed by histological examination of biopsy specimens. No hiatus hernia was seen. Oesophageal manometric recordings during $5 \mathrm{ml}$ swallows of water showed low amplitude, slowly propagated, peristaltic waves in the middle and lower oesophagus (fig 2(a)) with a mean amplitude of 47 and $25 \mathrm{~mm} \mathrm{Hg}$, respectively. These increased to means of 74 and $52 \mathrm{~mm} \mathrm{Hg}$ when the patient simulated her dystonic neck posture (fig 2(b)). The mean speed of propagation of peristaltic swallows was $2.5 \mathrm{~cm} / \mathrm{s}$ with the head in the midline, and $4.0 \mathrm{~cm} / \mathrm{s}$ while the head was rotated and tilted towards the left shoulder.

\section{PROGRESS}

She was started on sucralfate $500 \mathrm{mg}$, cisapride $3 \mathrm{mg}$, and ranitidine $15 \mathrm{mg}$, all taken four times a day. Over the next six weeks, however, she continued to vomit and make dystonic neck movements. Repeat endoscopy showed that the severe ulcerative oesophagitis was unchanged, and a Nissen fundoplication was therefore carried out. Three months after operation all her symptoms-including the abnormal posturing-had completely resolved. Further oesophageal manometry was considered ethically unjustifiable.

\section{Discussion}

The association between abnormal movements and gastro-oesophageal reflux with hiatus hernia was first recognised by Sandifer, ${ }^{1}$ and the association of abnormal posturing and oesophagitis without hiatus hernia has also been described. ${ }^{2}$ Characteristic 

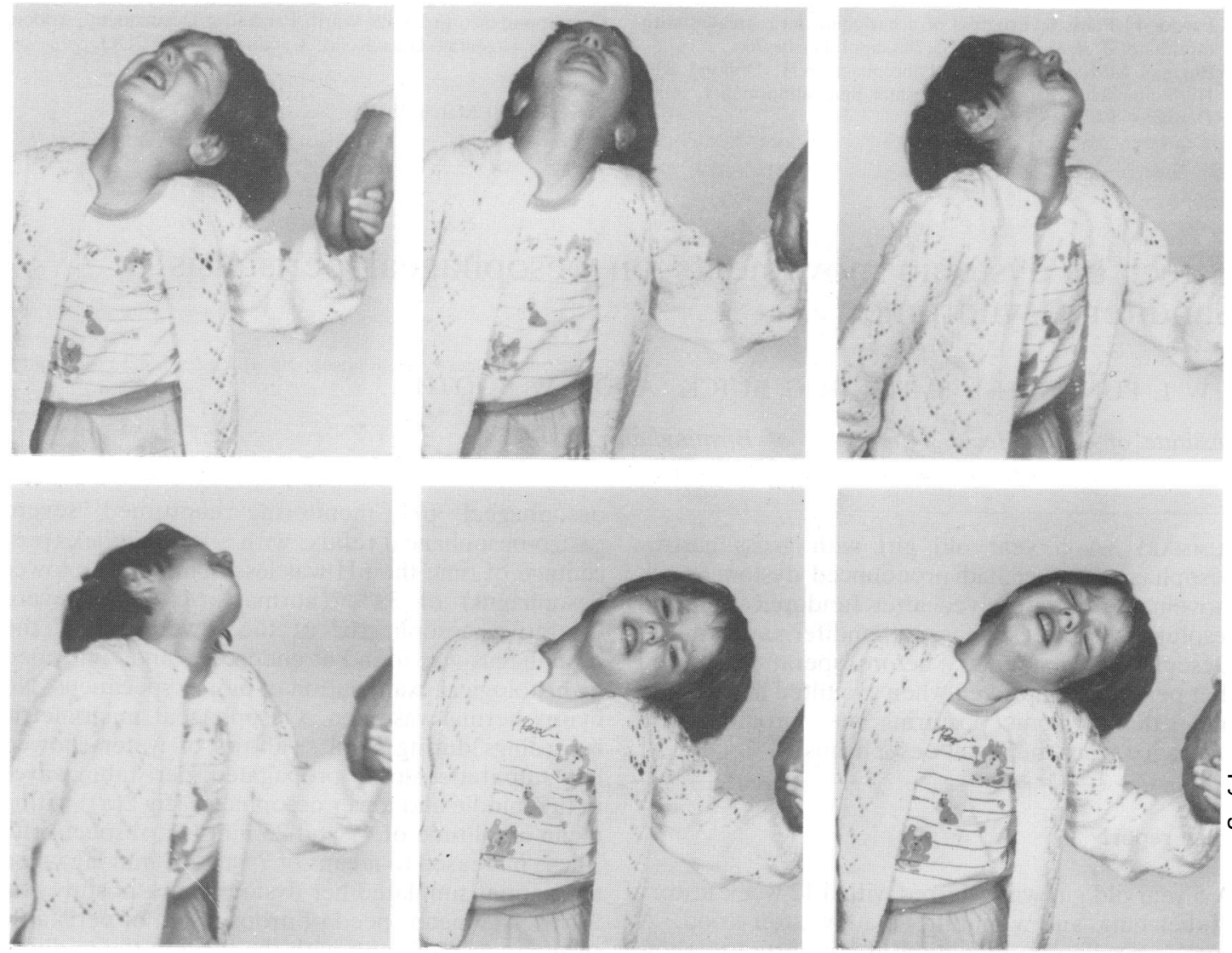

Fig 1 Dystonic neck movements associated with severe gastro-oesophageal reflux.

movements include extension and rotation of the neck. Some children allow their heads to hang in extension over the edge of the bed while lying supine. Dystonia does not occur during sleep, and once the gastro-oesophageal reflux has been treated effectively (either medically ${ }^{3}$ or surgically ${ }^{1}$ ) the abnormal movements cease. Children may initially be referred to one of a number of different specialists, including ophthalmologists, ${ }^{4}$ neurologists, ${ }^{13}$ or psychiatrists, ${ }^{3}$ and underlying gastrooesophageal reflux should be considered in all patients who present with dystonic neck movements and abnormal posturing. Most children with gastrooesophageal reflux, however, do not develop abnormal posture ${ }^{5}$ and the connection between reflux and dystonia has been a matter for speculation. It has been suggested that the movements in some way bring about symptomatic relief but the precise mechanism has not been elucidated. ${ }^{15}$

As far as we are aware, manometric studies have not previously been reported in a case of Sandifer's syndrome. In our patient the low amplitude and slow propagation of oesophageal peristalsis may have reflected a primary motility defect or been secondary to the oesophagitis. ${ }^{6}$ We were able to show that the dystonic posturing produced an increase in the velocity and amplitude of the peristaltic waves in the oesophagus, and we postulate that this would promote the clearance of acid from the lower oesophagus and thereby relieve the symptoms. We have not been able to reproduce these findings in three normal adult controls or in two children with oesophageal reflux but no dystonia, and the association between posture and 


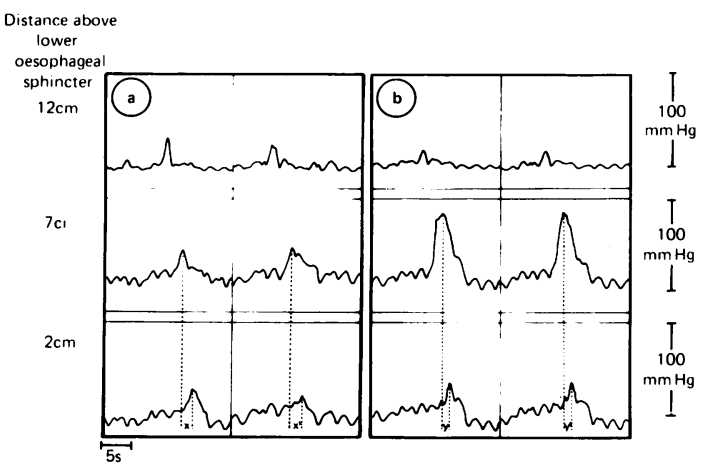

Simultaneous recordings from three sites in the oesophagus using a perfused manometry catheter

Fig 2 Three channel oesophageal manometry showing an increase in amplitude and velocity of peristalsis when head rotated and tilted towards the left shoulder. (a) Shows two representative swallows with $5 \mathrm{ml}$ boluses while head in the midline. Peristaltic waves are broad based and of low amplitude. (b) Shows two representative swallows with $5 \mathrm{ml}$ boluses while head rotated to the left. Amplitude of peristaltic waves is increased especially in middle channel. Distances $y$ and $y^{\prime}$ are less than $x$ and $x^{\prime}$ showing that peristaltic waves are travelling more rapidly in mid to lower oesophagus. oesophageal motility remains unclear. Manometric studies in future patients may help to explain the abnormal movements seen in this rare and intriguing disorder.

\section{References}

${ }^{1}$ Kinsbourne M. Hiatus hernia with contortions of the neck. Lancet 1964;i:1058-61.

2 Ramenofsky ML, Buyse M, Goldberg MJ, Leape LL. Gastroesophageal reflux and torticollis. Journal of Bone and Joint Surgery 1978;60:1140-1.

${ }^{3}$ Bray PF, Herbst JJ, Johnson DG, Book LS, Ziter FA, Condon VR. Childhood gastroesophageal reflux. Neurologic and psychiatric syndromes mimicked. JAMA 1977;237:1342-5.

4 O'Donnell JJ, Howard RO. Torticollis associated with hiatus hernia. Am J Ophthalmol 1971;71:1134-7.

5 Sutcliffe J. Torsion spasms and abnormal postures in children with hiatus hernia Sandifer's syndrome. In: HJ Kaufman, ed. Progress in pediatric radiology. Vol 2. Chicago: Karger, 1969: 190-7.

6 Cucchiara S, Staiano A, Di Lorenzo D, et al. Esophageal motor abnormalities in children with gastroesophageal reflux and peptic oesophagitis. J Pediatr 1986;108:907-10.

Correspondence to Dr JWL Puntis, Institute of Child Health, Francis Road, Edgbaston, Birmingham B16 8ET.

Accepted 20 April 1989

\title{
Obesity and diabetic control
}

\author{
S S ABUSREWIL AND D C L SAVAGE \\ Royal Hospital for Sick Children, Bristol
}

SUMmarY Children with diabetes mellitus are not significantly heavier than their peers, and those who are obese do not have poorer diabetic control.

Adults with insulin dependent diabetes are often obese, and this may adversely affect their diabetic control, resulting in complications. ${ }^{1} \mathrm{We}$ are unaware of any publication on the incidence of obesity in childhood diabetes or of its effect on diabetic control. In this study we report the incidence of obesity in children attending our diabetic clinic, and relate this to their diabetic control.

\section{Patients and methods}

One hundred and six children ( 58 boys and 48 girls) attending the diabetic clinic at the Bristol Children's
Hospital who had had diabetes for more than one year were studied over the 12 month period. Their mean age during the study period was 14.9 years (range 5-22), and their mean age at diagnosis was $8 \cdot 3$ years (range 1.3-15.9). The mean duration of their diabetes was $6 \cdot 4$ years (range 1-16.6). All the children were receiving quick and intermediate acting insulins twice daily, with the exception of three patients who used an insulin pump.

They were seen at intervals of three months, when their height and weight (measured with a Harpenden stadiometer) were recorded. Skinfold thickness (triceps and subscapular) was measured using a Harpenden skinfold caliper, and puberty was assessed clinically by the method of Tanner and Whitehouse. ${ }^{2}$ Each child's height, weight, and skinfold thickness was then taken as the average over visits during the year of investigation.

The children were regarded as overweight when 